\title{
Allergic fungal rhinosinusitis - a new staging system*
}

\author{
Carl M. Philpottt ${ }^{1,2}$, Allan Clark², Amin R. Javer ${ }^{1}$ \\ St Paul's Sinus Centre, Vancouver, British Columbia, Canada \\ 2 University of East Anglia, School of Medicine, Health Policy and Practice, Norwich, United Kingdom
}

SUMMARY Background: The existing Kupferberg post-operative endoscopic staging system for allergic fungal rhinosinusitis (AFRS) has 4 stages based on the 'global' appearance of one side of the nose. Patients may however show visual improvement and yet remain at the same stage due to persistence in one sinus cavity, thus making the staging system ineffective. The aim of this study was to validate a new system that allows greater sensitivity in characterising the inflammation seen endoscopically.

Methodology: A series of endoscopy videos of 50 patients with AFRS were retrospectively staged using a new ten-grade system, scoring each sinus cavity (maxillary, ethmoid, frontal and sphenoid) from 0 - 9 for increasing mucosal oedema and 1 point for the presence of fungal mucin giving a maximum score of 40 for each side of the nose. To assess reliability, 4 independent rhinologists were also asked to score the videos using the new system.

Results: A greater variety in the spectrum of mucosal disease was demonstrated with the new system allowing for a more descriptive analysis of its severity and its response, or lack of, to treatment. The inter-class correlation between the 6 total observers was 0.86 .

Conclusion: Use of the new staging system provides a more sensitive tool for following patients' progress post-operatively in allergic fungal rhinosinusitis and in determining their response to treatment.

Key words: allergic fungal rhinosinusitis, endoscopy, staging

\section{INTRODUCTION}

Allergic fungal rhinosinusitis (AFRS) may be considered a form of chronic rhinosinusitis (CRS) and accounts for 7 - 10\% of CRS. The name itself is a misnomer as a type I hypersensitivity reaction is not proven despite the evidence of the other key clinical features and perhaps the term 'reactive' fungal rhinosinusitis (RFRS) may be more appropriate in describing this condition. It was in 1994 that Bent and Kuhn defined the 5 diagnostic criteria for AFRS (Table 1) ${ }^{(1)}$; a modified version is utilised in our centres whereby immunocompetence replaces type I hypersensitivity, reflecting the group of characteristic patients seen in rhinologic practice.

These patients have a distinct clinical pattern of recurrent nasal poylposis and accumulation of fungal mucin. Their consistent clinical pattern is the key factor in their management as they require meticulous and complete endoscopic sinus surgery (see below) along with careful and regular follow-up in the outpatient clinic to try and prevent the polyp reformation and accumulation of mucin. With this in mind, Kupferberg et al. devised a staging system for endoscopic follow-up in these patients post-operatively (Table 2) ${ }^{(2)}$. It became apparent in our centre that this staging system had its limitations because it was common to see patients who had improved both symptomatically and endoscopically and yet had remained at the same stage based on one sinus cavity rather than the global picture. This became more pertinent when considering their response to treatment and new research treatment options. It therefore became necessary to devise a system ${ }^{(3)}$ which was more sensitive to the endoscopic changes seen in our patients. This study aims to demonstrate a new staging system and provide validation for this system which has already been used to demonstrate clinically significant changes in a clinical study in AFRS patients ${ }^{(4)}$.

\section{METHODS}

The study was approved by the University of British Columbia ethical review committee. The new staging system was devised 
Table 1. Bent \& Kuhn diagnostic criteria for RFRS

type I hypersensitivity confirmed by history, skin tests, or serology nasal polyposis

characteristic CT scan (double density sign)

eosinophilic mucus without fungal invasion into sinus tissue

positive fungal stain of sinus contents removed intraoperatively or during office endoscopy

Immunocompetence (replaces no 1 at St Paul's Sinus Centre)

Table 2. Kupferberg staging system for RFRS (Vancouver modified).

\begin{tabular}{ll}
\hline Stage & Endoscopic Findings \\
\hline 0 (A/B) & No mucosal oedema \\
I (A/B) & Mucosal oedema \\
II (A/B) & Polypoid oedema \\
III (A/B) & Sinus Polyps \\
\hline
\end{tabular}

A: without allergic mucin; B: with allergic mucin.

Table $3 \mathrm{a}$ and $3 \mathrm{~b}$. Philpott-Javer Endoscopic staging system for RFRS.

\begin{tabular}{|c|c|c|c|c|}
\hline Sinus cavity & Right & Mucin & Left & Mucin \\
\hline Frontal & $0-9$ & 1 & $0-9$ & 1 \\
\hline Ethmoid & $0-9$ & 1 & $0-9$ & 1 \\
\hline Maxillary & $0-9$ & 1 & $0-9$ & 1 \\
\hline Sphenoid & $0-9$ & 1 & $0-9$ & 1 \\
\hline Total & \multicolumn{2}{|c|}{40} & \multicolumn{2}{|c|}{40} \\
\hline Bilateral tota & & & & \\
\hline
\end{tabular}

\begin{tabular}{ll}
\hline Grading & State of mucosa \\
\hline 0 & No oedema \\
$1-3$ & Mucosal oedema (mild/moderate/severe) \\
$4-6$ & Polypoid oedema (mild/moderate/severe) \\
$7-9$ & Frank polyps (mild/moderate/severe) \\
\hline
\end{tabular}

for post-operative cases of AFRS. This was derived as a modification of the existing Kupferberg system ${ }^{(2)}$; each sinus cavity is scored on its own merit rather than as a collective whole. Each of the Kupferberg stages of mucosal oedema, polypoid oedema and frank polyps were expanded to each have grades of mild, moderate or severe. This allowed 9 stages of inflammatory changes to be allocated to each cavity; further consideration was then given to the presence of 'allergic' or reactive fungal mucin leading to a possible total score of 10 points for each cavity, 40 points for each side of the nose and 80 points for the total maximum bilateral score 3 (Tables $3 a$ and $b$ ).

Having been trialled in the outpatient clinic at St Paul's Sinus Centre over several months by the authors (ARJ and CMP), a

\section{New Endoscopic Staging for Allergic Fungal Sinusitis} Providence

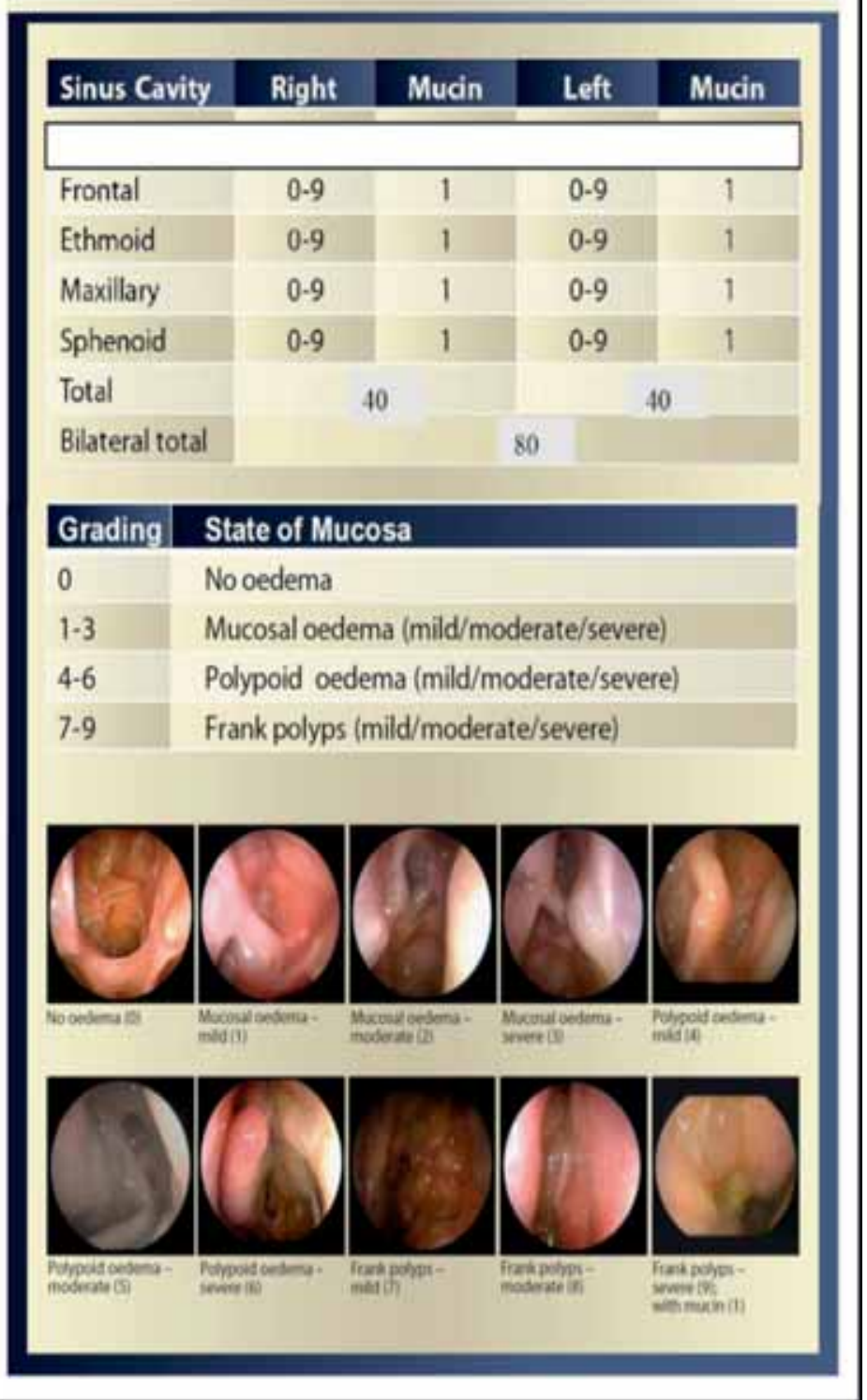

Figure 1. Poster for mucosal staging.

validation process was then undertaken. All patient endoscopy videos were taken from patients with AFRS diagnosed with the criteria listed in Table 1. This involved selecting 50 video clips (from the D-scope video archive) of routine outpatient endoscopy using a random number generator and sending them for anonymous review by 4 independent rhinologists. All of the video clips were selected from patients who met the diagnostic criteria in Table 1 and had previously undergone full computerassisted endoscopic sinus surgery bilaterally, with the endoscopic video being performed at least 2 months after surgery. (N.B. Surgery involved total uncinectomies, antrostomies, total ethmoidectomies, sphenoidotomies (Bolger approach), frontal sinusotomies and lavage of all cavities with amphoterecin B). With a descriptive chart as a guide (Figure 1), they were then 

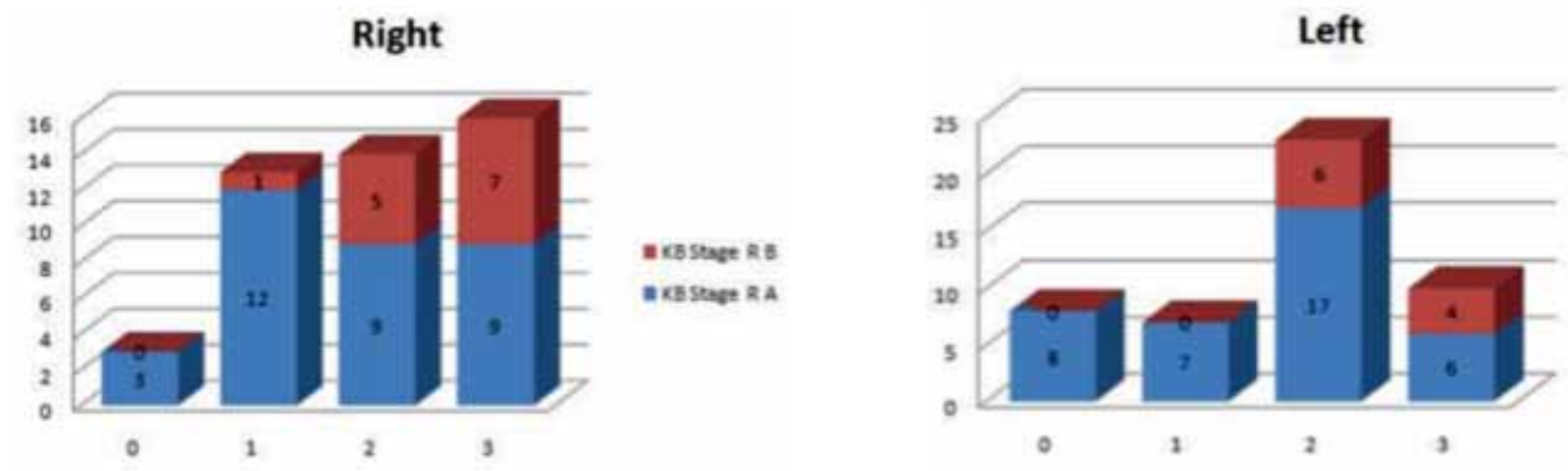

- Kastage Lo

exastage la

Figures 2a and 2b. Kupferberg Staging.

\section{P-J Stage $\mathbf{R}$}

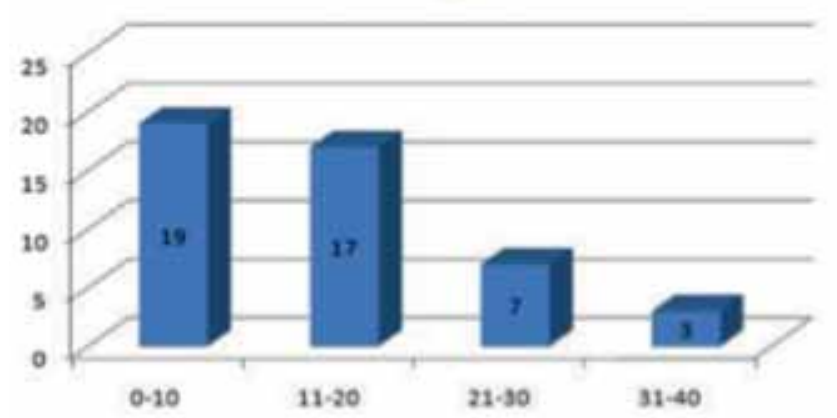

P-J Stage L

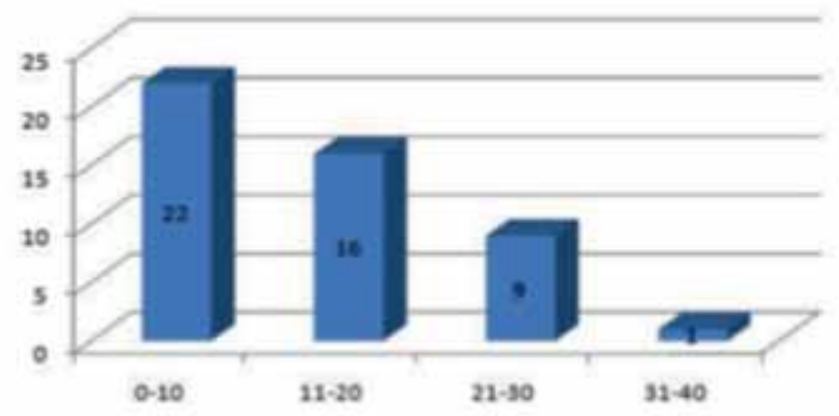

Figure $3 \mathrm{a}$ and $3 \mathrm{~b}$. Philpott-Javer Staging.

\section{Bilateral score}

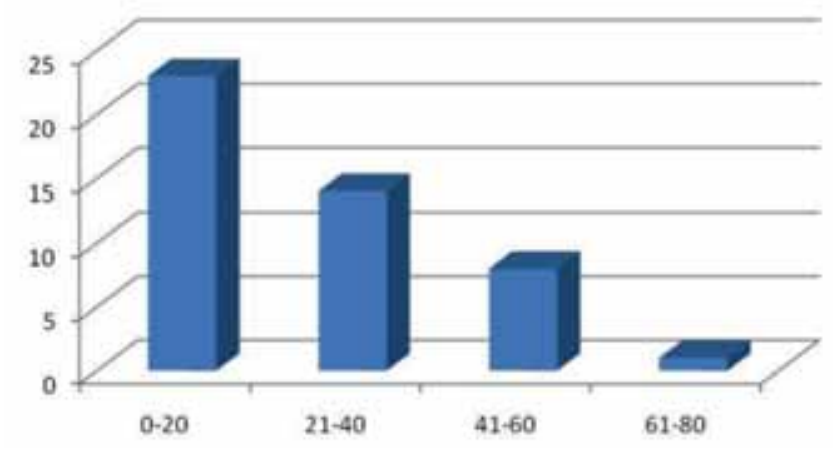

Figure 4. Bilateral combined score for AFRS patients using Philpott-Javer staging system.

asked to score all 50 videos using both the old Kupferberg system and the new Philpott-Javer system. A standard system of endoscopic examination ensured that all the videos provided visualisation of the 4 sinus cavities or at the very least their ostia.

These scores were then checked for inter-observer variability by calculating the intra-class correlation coefficient (ICC). The ICC is a standard measure of inter-rater reliability ${ }^{(5)}$.

\section{RESULTS}

The 50 patients ( 22 males and 28 females) whose videos were analysed had a mean age of 55 years (range 25 to 75 ). One video file corrupted and was excluded from the analysis. The remaining video clips had a left side missing in 1 patient and the right side in 2 patients resulting in 46 right and 48 left sets of sinus cavities being analysed (Table 4). Figures $2 \mathrm{a}$ and $2 \mathrm{~b}$ show the scoring for the videos using the Kupferberg system and Figures $3 \mathrm{a}$ and $3 \mathrm{~b}$ shows the scores for the new Philpott-Javer system (using the 80 point maximum). The Philpott-Javer staging is broken down in to brackets of 10 points to provide a means of comparing the data with the Kupferberg system. These bar charts clearly demonstrate how the new system sheds a different light on the spectrum of disease encountered in patients with AFRS with a larger proportion of patients receiving a lower score than they would have done using the Kupferberg system; the total bilateral score is depicted graphically in Figure 4. There are 18 patients rated as stage 3 in at least one nostril on the Kupferberg system; in the Philpott-Javer system, just 


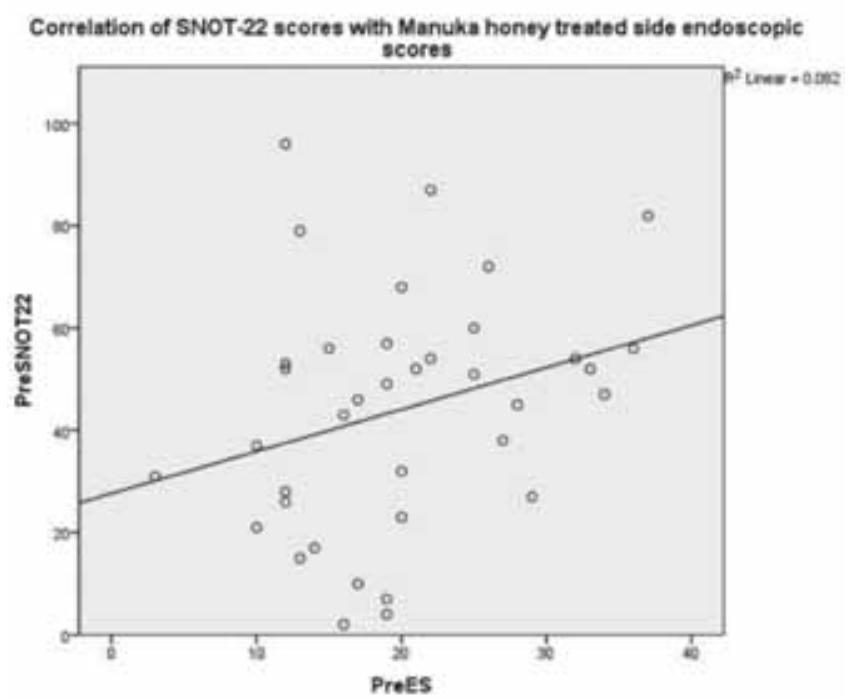

Figure 5. Correlation of Philpott-Javer staging and SNOT-22 scores in Manuka honey study.

one patient was rated in the 31 - 40 range. The inter-class correlation between the 6 total observers was 0.86 (95\% CI: 0.83 , $0.92)$ which rates as outstanding reliability ${ }^{(6)}$.

\section{DISCUSSION}

The results of this study show a clear distinction between the old Kupferberg system and the new Philpott-Javer system, which actually is generally more forgiving on the severity of oedema than the old. This mirrors the perception we had when reviewing patients in the outpatient clinic, i.e., having just one sinus cavity with severe oedema when the other cavities were not as severely affected could skew their staging result. This consequently allows the clinician to define the state of mucosal oedema in a cavity by giving a total score that reflects the whole picture rather than the worst affected cavity. The correlation between the independent assessors was above 0.8 and underlines the usefulness and reliability of this system for grading patients post-operatively. However, in this study we did not collect data which would allow the calculation of intra-rater reliability since each subject was assessed only once by each rhinologist. We suspect that the intra-rater reliability would be higher than the inter-rater reliabilty and we are currently designing studies to enable us to demonstrate this.

Whilst the authors appreciate that there are other endoscopic scoring systems such as the Lund-Kennedy system ${ }^{7}$, ${ }^{8)}$, the Philpott-Javer system is tailored more specifically to suit patients with AFRS. More recently, Wise et al devised a radiological system based on the degree of sinus expansion in 111 patients with AFRS ${ }^{(9)}$; this is certainly a useful marker for comparing patient severity pre-operatively but does not convey any advantages for post-operative monitoring in the outpatient clinic. In our centres we have mounted charts on the clinic wall to guide other members of the team when using the scoring system so that it can be recorded every time they

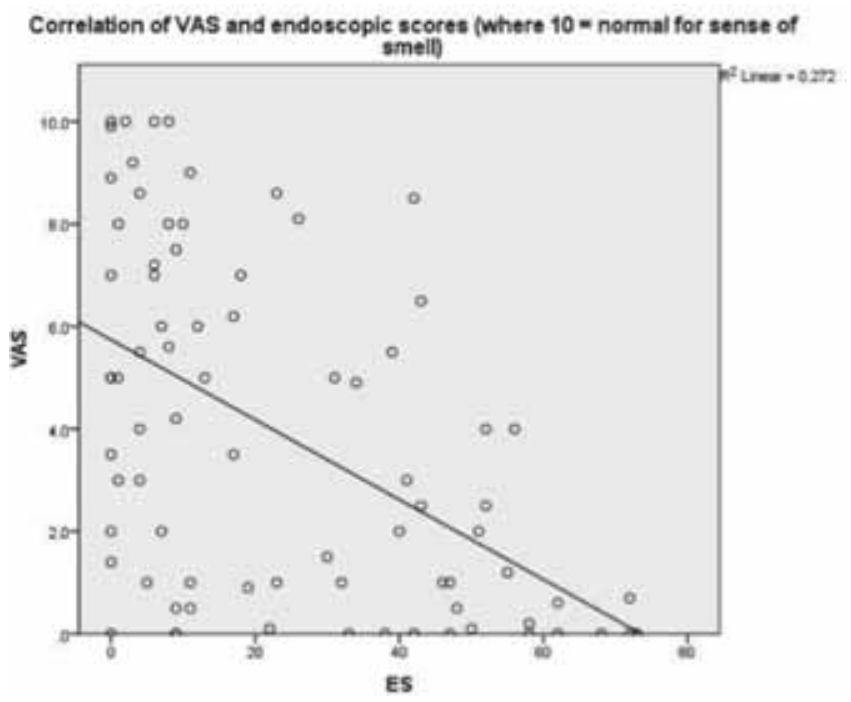

Figure 6. Correlation of Philpott-Javer staging and visual analogue scores in olfactory dysfunction study.

come to the clinic (Figure 1). Patients with AFRS require regular follow-up to ensure that their disease is well controlled and therefore good documentation of their condition is paramount. At our centres patients are seen at 6-12 week intervals depending on their response to treatment.

The added benefit when undertaking research trials with these patients, is that a scoring system such as ours enables greater ease of analysis since there is a greater range of variation and it is more likely to be representative of their current disease status. This system has now been used in other studies for treatments on patients with AFRS where there was a significant correlation between SNOT-22 scores and the Philpott-Javer staging $(\mathrm{r}=0.556, \mathrm{p}=0.01)^{\left({ }^{(10)}\right)}$ (Figure 5), and has shown to correlate well with the visual analogue symptom scores in a recent study on olfactory dysfunction in AFRS patients ${ }^{(4)}$ (Figure 6). If preferred, patients can be ranked as mild (1 - 20), moderate $(21-40)$, severe $(41-60)$ or extreme (61 - 80) based on the combined bilateral endoscopic staging, which may prove a useful context for planning future treatment.

\section{CONCLUSION}

This paper presents a new validated staging system that should become a useful tool for follow-up and research in post-operative patients with AFRS.

\section{ACKNOWLEDGEMENTS}

Our thanks to the independent assessors for giving up their time to review the videos or critique the staging system: Dr Heitham Gheriani, University of British Columbia, Canada; Dr Talal Alandejani, Ottawa-General Hospital Campus, Ottawa, Ontario, Canada; Dr Roy Thomas, San Antonio, Texas, USA; Dr Kwai-Onn Chan, Faculty of Medicine, National University of Singapore; Dr Karen Fong, California Sinus Centres, Walnut Creek, California, USA. 
Table 4. Endoscopic scoring data by patient.

\begin{tabular}{|c|c|c|c|c|c|c|c|c|c|c|c|c|c|c|}
\hline $\begin{array}{l}\text { Study } \\
\text { No }\end{array}$ & Sex & Age & CMP R & CMP L & ARJ R & ARJ L & HG R & HG L & RT R & RT L & KF R & KF L & TA R & TA L \\
\hline 1 & $\mathrm{~F}$ & 68 & 2 & 7 & 6 & 8 & 2 & 8 & 0 & 2 & 4 & 7 & 1 & 2 \\
\hline 2 & M & 54 & 18 & 21 & 20 & 14 & 16 & 9 & 16 & 10 & 21 & 20 & 12 & 11 \\
\hline 3 & $\mathrm{~F}$ & 75 & 19 & 15 & 22 & 13 & 15 & 12 & 24 & 5 & 20 & 26 & 23 & 22 \\
\hline 4 & $\mathrm{~F}$ & 56 & 9 & 6 & 8 & 12 & 9 & 16 & ND & ND & 8 & 10 & 3 & 11 \\
\hline 5 & $\mathrm{~F}$ & 50 & 28 & 26 & 30 & 22 & 23 & 21 & 30 & 26 & 25 & 32 & 23 & 22 \\
\hline 6 & $\mathrm{~F}$ & 53 & 2 & 6 & 3 & 6 & 3 & 3 & 3 & 1 & 9 & 7 & 1 & 0 \\
\hline 7 & $\mathrm{~F}$ & 52 & 4 & 0 & 7 & 4 & 6 & 2 & 1 & 0 & 5 & 4 & 0 & 0 \\
\hline 8 & M & 36 & 27 & 20 & 28 & 24 & 23 & 28 & 33 & 35 & 25 & 25 & 23 & 25 \\
\hline 9 & M & 66 & 24 & 24 & 26 & 18 & 25 & 20 & 29 & 23 & 24 & 14 & 18 & 11 \\
\hline 10 & $\mathrm{~F}$ & 71 & 17 & 14 & 13 & 16 & 10 & 18 & 10 & 10 & 16 & 21 & 3 & 11 \\
\hline 11 & $\mathrm{~F}$ & 46 & 12 & 6 & 12 & 10 & 8 & 8 & 14 & 8 & 13 & 8 & 7 & 6 \\
\hline 12 & $\mathrm{~F}$ & 73 & 4 & 3 & 7 & 6 & 4 & 4 & 1 & 5 & 5 & 4 & 4 & 2 \\
\hline 13 & $\mathrm{~F}$ & 45 & 7 & 14 & 8 & 13 & 8 & 12 & 8 & 12 & 9 & 11 & 2 & 2 \\
\hline 14 & $\mathrm{~F}$ & 71 & 18 & 16 & 22 & 18 & 21 & 13 & 20 & 12 & 25 & 20 & 31 & \\
\hline 15 & $\mathrm{~F}$ & 73 & 10 & 9 & 12 & 11 & 8 & 5 & 6 & 3 & 8 & 5 & 3 & 2 \\
\hline 16 & $\mathrm{M}$ & 56 & 35 & 11 & 31 & 9 & 29 & 7 & 32 & 3 & 35 & 12 & 34 & 1 \\
\hline 17 & M & 74 & 6 & 9 & 7 & 12 & 4 & 1 & 4 & 5 & 11 & 13 & 1 & 0 \\
\hline 18 & $\mathrm{~F}$ & 37 & N/A & 1 & N/A & 3 & N/A & 4 & N/A & 3 & 0 & 6 & & 3 \\
\hline 19 & M & 65 & 36 & 36 & 35 & 36 & 30 & 36 & 36 & 36 & 32 & 32 & 26 & 33 \\
\hline 20 & $\mathrm{M}$ & 45 & 28 & 14 & 26 & 14 & 23 & 12 & 27 & 16 & 29 & 19 & 27 & 13 \\
\hline 21 & $\mathrm{~F}$ & 60 & 13 & 26 & 9 & 25 & 13 & 15 & 7 & 18 & 16 & 27 & 10 & 23 \\
\hline 22 & M & 49 & 11 & 17 & 13 & 15 & 11 & 10 & 10 & 14 & 17 & 19 & 14 & 14 \\
\hline 23 & $\mathrm{~F}$ & 55 & 11 & 7 & 10 & 10 & 7 & 7 & 12 & 8 & 16 & 14 & 5 & 6 \\
\hline 24 & $\mathrm{~F}$ & 46 & N/A & 16 & N/A & ND & ND & ND & ND & ND & 0 & 0 & & 8 \\
\hline 25 & $\mathrm{~F}$ & 53 & 13 & 15 & 18 & 17 & 16 & 12 & 16 & 18 & 19 & 22 & 17 & 11 \\
\hline 26 & $\mathrm{~F}$ & 72 & 2 & 1 & 1 & 0 & 1 & 1 & 4 & 0 & 4 & 6 & 0 & 0 \\
\hline 27 & $\mathrm{M}$ & 67 & 17 & 25 & 22 & 28 & 17 & 23 & 30 & 23 & 26 & 30 & 28 & 28 \\
\hline 28 & M & 48 & 7 & 11 & 6 & 7 & 18 & 10 & 9 & 15 & 21 & 18 & 3 & 11 \\
\hline 29 & M & 42 & 22 & 14 & 23 & 16 & 15 & 9 & 21 & 20 & 20 & 11 & 13 & 10 \\
\hline 30 & $\mathrm{M}$ & 42 & 11 & 23 & 6 & 23 & 6 & 24 & 9 & 21 & 11 & 21 & 0 & 21 \\
\hline 31 & M & 75 & 0 & 0 & 1 & 2 & 2 & 6 & 6 & 8 & 6 & 6 & 0 & 0 \\
\hline 32 & M & 50 & 5 & 5 & 4 & 7 & 7 & 8 & 6 & 6 & 6 & 6 & 1 & 2 \\
\hline 33 & $\mathrm{~F}$ & 55 & 3 & 5 & 3 & 7 & 2 & 10 & 5 & 12 & 4 & 11 & 0 & 6 \\
\hline 34 & $\mathrm{~F}$ & 59 & 11 & 5 & 14 & 6 & 17 & 7 & 16 & 11 & 16 & 7 & 12 & 5 \\
\hline 35 & $\mathrm{~F}$ & 52 & N/A & 0 & N/A & 0 & ND & ND & ND & ND & 0 & 0 & & 0 \\
\hline 36 & $\mathrm{~F}$ & 58 & 26 & N/A & ND & N/A & ND & ND & ND & ND & 0 & 0 & & \\
\hline 37 & $\mathrm{~F}$ & 20 & 11 & 7 & 14 & 7 & 9 & 6 & 10 & 4 & 14 & 9 & 4 & 4 \\
\hline 38 & $\mathrm{~F}$ & 26 & 19 & 20 & 25 & 14 & 17 & 18 & 20 & 19 & 21 & 23 & 24 & 12 \\
\hline 39 & M & 68 & 22 & 16 & 24 & 16 & 16 & 11 & 25 & 18 & 25 & 25 & 19 & 10 \\
\hline 40 & $\mathrm{~F}$ & 59 & 2 & 8 & 1 & 9 & 5 & 14 & 7 & 15 & 7 & 21 & 0 & 10 \\
\hline 41 & M & 64 & 2 & 6 & 1 & 1 & 0 & 0 & 4 & 4 & 5 & 5 & 1 & 3 \\
\hline 42 & M & 46 & 6 & 13 & 6 & 10 & 12 & 11 & 12 & 12 & 8 & 11 & 5 & 5 \\
\hline 43 & $\mathrm{~F}$ & 60 & 0 & 0 & 3 & 2 & 4 & 5 & 5 & 4 & 5 & 4 & 1 & 0 \\
\hline 44 & $\mathrm{~F}$ & 25 & 19 & 25 & 24 & 24 & 23 & 27 & 22 & 28 & 23 & 32 & 20 & 19 \\
\hline 45 & $\mathrm{M}$ & 49 & 2 & 6 & 5 & 9 & 6 & 9 & ND & ND & 9 & 9 & 4 & 3 \\
\hline 46 & $\mathrm{M}$ & 60 & 24 & 27 & 25 & 24 & 22 & 24 & 28 & 27 & 23 & 21 & 27 & 15 \\
\hline 47 & $\mathrm{~F}$ & 53 & 1 & 0 & 6 & 2 & 1 & 2 & 4 & 5 & 5 & 4 & 1 & 1 \\
\hline 48 & M & 60 & 3 & 4 & 7 & 3 & 6 & 4 & 6 & 5 & 8 & 7 & 2 & 1 \\
\hline 49 & M & 53 & 14 & 1 & 12 & 7 & 9 & 4 & 16 & 6 & 16 & 10 & 9 & 4 \\
\hline
\end{tabular}


There are no financial disclosures or conflicts of interest.

\section{REFERENCES}

1. Bent JP, 3rd, Kuhn FA. Diagnosis of allergic fungal sinusitis. Otolaryngol Head Neck Surg. 1994; 111: 580-588.

2. Kupferberg SB, Bent JP, 3rd, Kuhn FA. Prognosis for allergic fungal sinusitis. Otolaryngol Head Neck Surg. 1997; 117: 35-41.

3. Philpott C, Javer A. A novel endoscopic staging system for allergic fungal sinusitis. Rhinology World. 2009; Philadelphia, USA.

4. Philpott C, Thamboo A, Lai L, et al. Olfactory dysfunction in allergic fungal rhinosinusitis. Arch Otolaryngol - Head Neck Surg (in press).

5. Shrout PE, Fleiss JL. Intraclass correlations: uses in assessing rater reliability. Psychol Bull. 1979; 86: 420-428.

6. Landis JR, Koch GG. The measurement of observer agreement for categorical data. Biometrics. 1977; 33: 159-174.

7. Lund VJ, Kennedy DW. Staging for rhinosinusitis. Otolaryngol Head Neck Surg. 1997; 117(3 Pt 2): S35-40.

8. Lund VJ, Kennedy DW. Quantification for staging sinusitis. The Staging and Therapy Group. Annals Otol, Rhinology Laryngol.
1995; 167: 17-21.

9. Wise SK, Rogers GA, Ghegan MD, Harvey RJ, Delgaudio JM, Schlosser RJ. Radiologic staging system for allergic fungal rhinosinusitis (AFRS). Otolaryngol Head Neck Surg. 2009; 140: 735-740.

10. Thamboo A, Thamboo A, Philpott C, Clark A, Javer A, editors. A Single Blind Study of Manuka Honey in Allergic Fungal Rhinosinusitis. Rhinology World. 2009; Philadelphia.

Mr Carl Philpott

School of Medicine, Health Policy and Practice University of East Anglia

Norwich

NR4 7TJ

United Kingdom

Tel: +44-(0)1603-591 105

E-mail: C.Philpott@uea.ac.uk

\section{9th INTERNATIONAL COURSE IN ADVANCED SINUS SURGERY TECHNIQUES}

Dissection course with fresh frozen cadaver heads

Teacher of Honour:

Prof. Manuel Bernal Sprekelsen

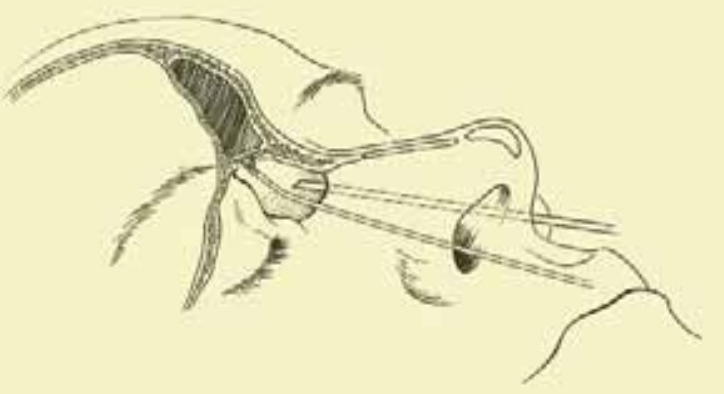

March 22-23 March, 2012

Department of Otorhinolaryngology

Academic Medical Center of the University

of Amsterdam

The Netherlands

For further information contact Wytske J. Fokkens, MD, PhD ENT dept. AMC Course Secretariat

Tel: 0031205668586 / Fax 0031205669573

Email:m.b.vanhuiden@amc.uva.nl 